\title{
Impact of air pollution on hospital admissions in Southwestern Ontario, Canada: Generating hypotheses in sentinel high-exposure places
}

\author{
Karen Y Fung*1, Isaac N Luginaah² and Kevin M Gorey ${ }^{3}$
}

Address: ${ }^{1}$ Department of Mathematics \& Statistics, University of Windsor, Windsor, Ontario, N9B 3P4 and McLaughlin Centre, Institute of Population Health, University of Ottawa, Ottawa, Ontario K1N 6N5, Canada, ²Department of Geography, University of Western of Ontario,

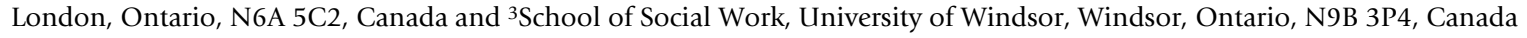

Email: Karen Y Fung* - kfung@uwindsor.ca; Isaac N Luginaah - iluginaa@uwo.ca; Kevin M Gorey - gorey@uwindsor.ca

* Corresponding author

Published: 5 July 2007

Environmental Health 2007, 6:18 doi:10.1186/1476-069X-6-18
Received: 10 April 2007

Accepted: 5 July 2007

This article is available from: http://www.ehjournal.net/content/6////8

(c) 2007 Fung et al; licensee BioMed Central Ltd.

This is an Open Access article distributed under the terms of the Creative Commons Attribution License (http://creativecommons.org/licenses/by/2.0), which permits unrestricted use, distribution, and reproduction in any medium, provided the original work is properly cited.

\begin{abstract}
Background: Southwestern Ontario (SWO) in Canada has been known as a 'hot spot' in terms of environmental exposure and potential effects. We chose to study 3 major cities in SWO in this paper. We compared age-standardized hospital admission ratios of Sarnia and Windsor to London, and to generate hypotheses about potential pollutant-induced health effects in the 'Chemical Valley', Sarnia.

Methods: The number of daily hospital admissions was obtained from all hospitals in London, Windsor and Sarnia from January I, 1996 to December 3I, 2000. We used indirect age adjustment method to obtain standardized admissions ratios for males and females and we chose London as the reference population. This process of adjustment was to apply the age-specific admission rates of London to the population of Sarnia and Windsor in order to yield expected admissions. The observed number of admissions was then compared to the expected admissions in terms of a ratio. These standardized admissions ratios and their corresponding confidence intervals were calculated for Sarnia and Windsor.
\end{abstract}

Results: Our findings showed that Sarnia and Windsor had significantly higher age-adjusted hospital admissions rates compared to London. This finding was true for all admissions, and especially pronounced for cardiovascular and respiratory admissions. For example, in 1996, the observed number of admissions in Sarnia was 3.I I (Cl: 2.80, 3.44) times for females and 2.83 (Cl: $2.54,3.14$ ) times for males as would be expected by using London's admission rates.

Conclusion: Since hospital admissions rates were significantly higher in 'Chemical Valley' as compared to both London and Windsor, we hypothesize that these higher rates are pollution related. A critical look at the way ambient air quality and other pollutants are monitored in this area is warranted. Further epidemiological research is needed to verify our preliminary indications of harmful effects in people living in 'Chemical Valley'. 


\section{Background}

In Canada, several reports have been published linking environmental pollution to adverse population health in various cities [1-9]. These reports have consistently shown that Southwestern Ontario (SWO) is second to none as a 'hot spot' in terms of environmental exposure and potential effects [8-11]. This is because the region is very industrialized and communities in this region are exposed to repeated episodes of short-term and long-range transport of air pollutants $[5,8,12]$. In this area, transported air pollution is characterized by low levels of primary gaseous pollutants $\left(\mathrm{SO}_{2}\right.$ and $\left.\mathrm{NO}_{2}\right)$ and moderately elevated concentrations of particles and ozone [5]. According to these authors, episodes of elevated sulfate and ozone concentrations occur frequently throughout the region, especially during the summer and early fall. Many environmental pollutants such as particulate pollutants resulting from the heavy traffic on highways in the region are generated both locally and regionally, and can be carried a long way by winds, affecting areas far removed from the source of the pollution. Also, data analyses strongly indicate that neighboring US states (Ohio, Illinois and Michigan) are significant contributors to elevated levels of ozones and inhaled particles in the region (Ontario Ministry of the Environment (MOE) [13].

There are three major cities in SWO: London, Windsor and Sarnia (Figure 1). The city of London $\left(42^{\circ} 59^{\prime} 00^{\prime \prime} \mathrm{N}\right.$ $\left.-81^{\circ} 14^{\prime} 00^{\prime \prime} \mathrm{W}\right)$ is located along Highway 401 . The city is noted for its economic diversity and is the home of many branches of industry, corporate offices, medical and educational facilities. It is also a manufacturing, distribution and financial center. Using 1981-1991 data, Burnett et al. [8], found that London has the third highest (10\%) increased risk of death attributable to change in mean air pollution in 11 Canadian cities. Nevertheless, as compared to Windsor and Sarnia, London is usually referred to as a clean city.

The city of Windsor is located $42^{\circ} 18^{\prime} \mathrm{N}, 83^{\circ} 01^{\prime} \mathrm{W}$. The city has major industries that include three automobile assembly plants, an engine plant and a foundry, and a scrapmetal recycling plant. In addition to the outstanding problem of transboundary air and water pollution from Ohio, Illinois and, Michigan, the city is immediately downwind of major steel mills with associated coking operations in Detroit; the wastewater treatment plant of the city of Detroit and associated sludge incineration facilities, and a major power plant which until recently was coal fired. Consequently, Windsor and the surrounding communities have been identified as an "Area of Concern" (AOC), and is in need of further health investigation [9]. A community-health profile of Windsor by Gilbertson and Brophy, suggested 'alarming trends' of mortality and morbidity higher than the rest of the province of Ontario

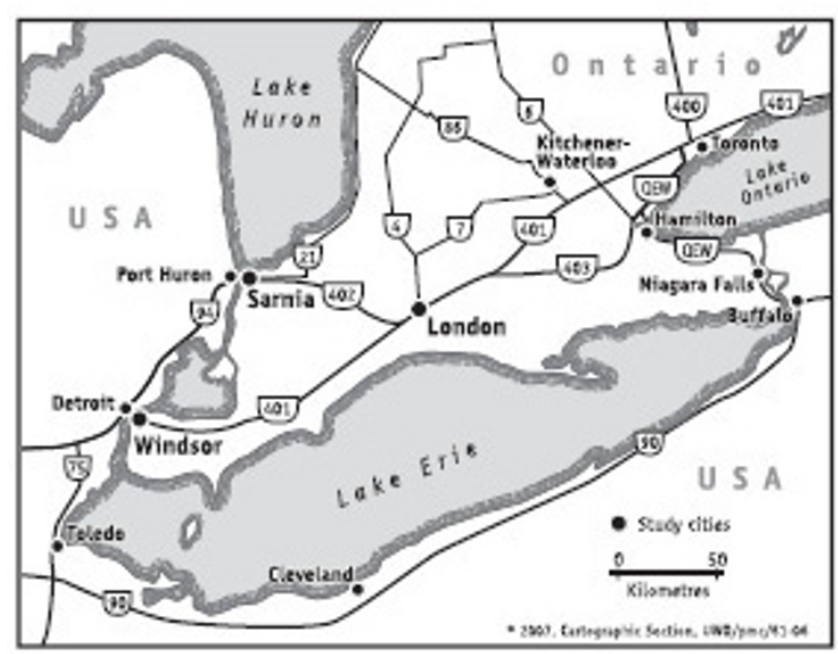

Figure I

Map of Southwest Ontario, Canada.

[10]. This work aroused a lot of public sentiments and several calls were made for further investigation in what may be happening in the entire region.

Sarnia is located $\left(42^{\circ} 18^{\prime} \mathrm{N}, 83^{\circ} 01^{\prime} \mathrm{W}\right)$. The city is often referred to as 'Chemical Valley', named because it is a centre for more than $40 \%$ of Canada's chemical industry, with major companies like Bayer, Dow Canada, Nova Chemicals and Suncor all having plants located there. These industries are all clustered along the St. Clair River. This area is also the home of Safety-Kleen, one of the largest landfill sites in Canada. With the large number of chemical industry, residents are exposed to a variety of pollutants at work and home. Sarnia is located within the St. Clair River AOC. Three of the major industrial facilities located in Sarnia together contribute more than $16 \%$ of the over 605 million kilograms of suspected respiratory toxicants released by the Top 10 Ontario facilities. In addition to air pollution linked to smog and asthma, other pollutants are released into the air that may affect the health of children and adults and the environment, including lead, mercury, benzene and nickel. Some, like lead and mercury, can be harmful to children's development. Others, like nickel and benzene, are associated with cancer [14].

Gilbertson reported higher rates of hospitalization for cerebral palsy in males in the Great Lakes communities and suggested this as a useful and reliable indicator of community exposures to methylmercury [15]. Mercury is one of the prototypical persistent toxic substances, along with the organochlorine compounds, that have been the central concern of environmental scientists working on the Great Lakes Water Quality Agreement for more than 30 
years [16]. Further concerns about health problems in the 'Chemical Valley' were raised when a recent study in a first Nations Reserve indicated a declining sex ratio $(2: 1)$ in favour of girls [17]. This drew a lot of media attention and public worry not only in the reserve, but in Sarnia at large.

Both Windsor and Sarnia are located at major Canada-US border crossing points. The terrorist attack of September 11, 2001 (9/11) also brought additional concerns about the effects of air pollution in the region, especially along Highways 401 and 402 transportation corridors. With more vigorous security policies across the US/Canada border-crossing points, there have been increasing delays resulting in long lines of trucks on the streets and highways [18]. The idling trucks are spewing toxic pollutants from their archaic exhaust systems into the air, and prevailing wind carries these pollutants to many areas in the region, further subjecting the entire region to more ambient pollution.

As part of a larger study to investigate environmental health effects and their potential determinants in the region, the aim of this paper is to compare the age-standardized hospital admission ratios of Sarnia, Windsor and London, to generate hypotheses about the adverse health effects of pollution in such highly exposed places as 'Chemical Valley'.

\section{Methods}

Hospital admission records for Ontario Health Insurance Plan (OHIP) patients were obtained from the Canadian Institute for Health Information's (CIHI) Discharge Abstract Database (DAD) for all the hospitals in Sarnia, Windsor and London, Ontario between January 1, 1996 and December 31, 2000. All hospital admissions, admissions with a primary diagnosis of respiratory diseases (based on ICD-9 codes of 460-519), and cardiovascular diseases (ICD-9 codes of 428, 410-414, 427) were analyzed.

Admissions rates for males and females were indirectly age-adjusted. The city of London was chosen as the standard for adjustment because it is the largest of the three cities under study and is considered as the 'cleanest' city. The process of indirect adjustment involves applying the agespecific admission rates of the standard population to a population of interest (Sarnia or Windsor) to yield a number of 'expected' admissions. This process is equivalent to asking, what would be the number of admissions in Sarnia (or Windsor) if people in Sarnia (Windsor) were hospitalized at the same age-specific rate as people in London. The standardized admissions ratio (SAR) of Sarnia (or Windsor) is calculated by the formula [19]:

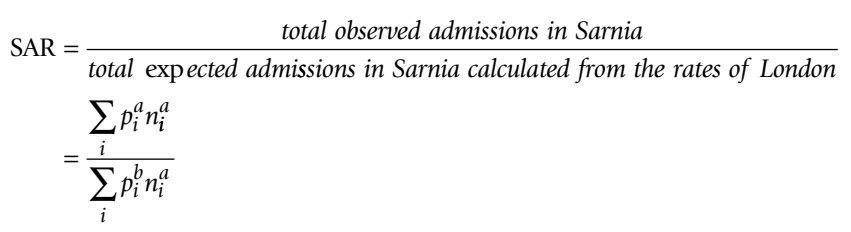

where $p_{i}^{a}$ is a age-specific admissions rate in Sarnia for age group i

$n_{i}^{a}$ is the population size in Sarnia in age group $\mathrm{i}$

$p_{i}^{b}$ is the age-specific admissions rate in London for age group i.

The following age categories were used in the adjustment: $0-4,5-14,15-19,20-24,25-54,55-64,65-74, \geq 75$ years.

If the SAR were greater than 1 , it would mean that more admissions were observed in Sarnia than would be expected based on rates from London.

The lower and upper limits of the 95\% confidence interval [19] were:

$$
\begin{gathered}
\text { lower limit }=(1-\sqrt{O})^{2} / E \\
\text { upper limit }=(1+\sqrt{O+1})^{2} / E
\end{gathered}
$$

where $\mathrm{O}=$ observed number of admissions in Sarnia (or Windsor), numerator of SAR

$\mathrm{E}=$ expected number of admissions in Sarnia (or Windsor), denominator of SAR.

\section{Results}

The population size, number of all hospital admissions, admissions due to cardiovascular diseases and respiratory disease admissions for males and females in the three cities from 1996 to 2000 are presented in Table 1. Crude rates can be calculated by dividing the number of admissions by the corresponding population size in a given year.

Table 2 presents the age-standardized admission ratios and their 95\% confidence intervals for Sarnia and Windsor compared to London. Since all of the SARs are greater than 1.00 here and all of their confidence intervals do not include 1.00, we concluded that both Sarnia and Windsor had significantly higher admissions rates than London for males and females from 1996 to 2000. For all admissions, 
Table I: Population size, number of hospital admissions for London, Windsor and Sarnia from I996 to 2000.

\begin{tabular}{|c|c|c|c|c|c|c|c|}
\hline Gender & City & & 1996 & 1997 & 1998 & 1999 & 2000 \\
\hline \multirow[t]{12}{*}{ Male } & London & Pop. size & 192750 & 196046 & 199342 & 202638 & 205934 \\
\hline & & All adm. & 4884 & 4424 & 4345 & 4734 & 4482 \\
\hline & & Cardio. & 1636 & 1520 & 1475 & 1666 & $149 \mid$ \\
\hline & & Resp. & 540 & 554 & 571 & 569 & 556 \\
\hline & Windsor & Pop. size & 135925 & 139039 & 142153 & 145267 & $|4838|$ \\
\hline & & All adm. & 5178 & 4782 & 4801 & 4851 & 4323 \\
\hline & & Cardio. & 1599 & 1634 & 1556 & 1588 & 1496 \\
\hline & & Resp. & 825 & 767 & 782 & 818 & 633 \\
\hline & Sarnia & Pop. size & 41950 & 42097 & 42244 & 42391 & 42538 \\
\hline & & All adm. & 1934 & 1809 & 1767 & 1622 & 1671 \\
\hline & & Cardio. & 699 & 678 & 709 & 625 & 671 \\
\hline & & Resp. & 355 & 290 & 280 & 284 & 246 \\
\hline \multirow[t]{12}{*}{ Female } & London & Pop. size & 205855 & 209329 & 212803 & 216277 & 219751 \\
\hline & & All adm. & 4185 & 3990 & 3758 & 3965 & 3879 \\
\hline & & Cardio. & 1198 & 1204 & 1064 & 1100 & 1124 \\
\hline & & Resp. & 521 & 502 & 571 & 624 & 525 \\
\hline & Windsor & Pop. size & 142755 & |4548| & 148207 & 150933 & 153659 \\
\hline & & All adm. & 4802 & 4569 & 4539 & 4458 & 4367 \\
\hline & & Cardio. & 1413 & 1443 & 1392 & 1309 & 1419 \\
\hline & & Resp. & 769 & 650 & 765 & 809 & 647 \\
\hline & Sarnia & Pop. size & 44525 & 44747 & 44969 & 45191 & 45413 \\
\hline & & All adm. & 1860 & $|68|$ & 1645 & 1563 & 1588 \\
\hline & & Cardio. & 647 & 604 & 564 & 552 & 606 \\
\hline & & Resp. & 368 & 296 & 292 & 236 & 238 \\
\hline
\end{tabular}

the observed ratio in Sarnia ranged from 1.47 to 1.90. For cardiovascular and respiratory admissions, the ratios were even more pronounced, reaching over three times the rate of London for female respiratory admissions in 1996.

The Windsor rates were somewhere between Sarnia and London and were all significantly higher than London. Sarnia had significantly higher admission rates than Windsor in all cases except for three: respiratory admissions for males in 1998; all admissions for males in 1999; and respiratory admissions for both males and females in 1999. Taken together, these findings certainly seem to sound an alarm. Hospitalization rates in this study's sentinel high-exposure city, Sarnia - in Ontario's 'Chemical Valley' - were much higher than in cities with less air pollution exposure.

To investigate if air pollution may be a factor for the high hospitalization rates in Sarnia, we gathered hourly data of some air pollutants from the monitoring stations obtained from the Ontario Ministry of the Environment. Summary statistics for the pollutants $\mathrm{SO}_{2}, \mathrm{NO}_{2}, \mathrm{O}_{3}$, and CO from January 1, 1996 to December 31, 2000 are displayed in Table 3 for London, Windsor and Sarnia. All the means of the pollutants are below the ambient air quality criteria (AAQC) set by the Ontario Ministry of the Environment in 2000. During this study period of five years, Sarnia had the highest overall means in $\mathrm{SO}_{2}$ and $\mathrm{O}_{3}$. The $\mathrm{SO}_{2}$ concentration in Sarnia exceeded the AAQC at least one time with an overall maximum of $110.17 \mathrm{ppb}$. Windsor had the highest overall means for $\mathrm{NO}_{2}$ and $\mathrm{CO}$. The number of missing values for each data set is also given in Table 3. Sarnia had more missing data values compared to London and Windsor. Furthermore, it was more likely to encounter missing data gaps of seven or more days, making any approximation of the missing data by moving averages or any other methods nearly impossible. The relatively large number of missing values in Sarnia may have affected the means reported here.

\section{Discussion}

We compared age adjusted admissions ratios for the three major cities in SWO with the aim of generating hypotheses as to what could be happening in these cities. Sarnia generally had the highest overall admission rates, while London had the lowest rates with Windsor in between them. This pattern that may be characterized as an ecolog- 
Table 2: Aged-standardized admissions ratio* (and 95\% confidence interval) of Windsor and Sarnia compared to London.

\begin{tabular}{|c|c|c|c|c|c|c|}
\hline \multirow[t]{4}{*}{ Windsor } & \multicolumn{6}{|c|}{ All Admissions } \\
\hline & & 1996 & 1997 & 1998 & 1999 & 2000 \\
\hline & Male & $1.49(1.45,1.54)$ & $1.53(1.48,1.57)$ & $1.57(\mathrm{I} .52, \mathrm{I} .6 \mathrm{I})$ & $1.46(1.42,1.50)$ & $1.381 .34,1.42)$ \\
\hline & Female & $1.63(1.59,1.68)$ & $1.64(1.59,1.69)$ & $1.74(1.69,1.79)$ & $1.631 .58,1.68)$ & $1.64(1.59,1.69)$ \\
\hline \multirow[t]{2}{*}{ Sarnia } & Male & $1.71(1.60,1.76)$ & $1.73(1.65,1.81)$ & $1.73(\mathrm{I} .65, \mathrm{I} .8 \mathrm{I})$ & $1.47(1.40,1.54)$ & $1.61(1.53,1.69)$ \\
\hline & Female & $1.90(1.87,2.05)$ & $1.86(1.77,1.95)$ & $1.94(1.84,2.03)$ & $1.76(1.67,1.85)$ & $1.82(1.73,1.91)$ \\
\hline \multicolumn{7}{|c|}{ All Cardiovascular Admissions } \\
\hline & & 1996 & 1997 & 1998 & 1999 & 2000 \\
\hline \multirow[t]{2}{*}{ Windsor } & Male & $1.37(1.30,1.44)$ & $1.51(1.44,1.59)$ & $1.50(1.42,1.57)$ & $1.36(1.29,1.43)$ & $\mathrm{I} .44(\mathrm{I} .37, \mathrm{I} .52)$ \\
\hline & Female & $1.67(1.58,1.76)$ & $1.71(1.62,1.80)$ & $1.88(1.78,1.99)$ & $1.79(1.64,1.83)$ & $1.85(1.76,1.95)$ \\
\hline \multirow[t]{2}{*}{ Sarnia } & Male & $1.78(1.65,1.92)$ & $1.85(1.71,2.00)$ & $2.01(1.86,2.16)$ & $1.58(1.45,1.70)$ & $1.91(1.77,2.06)$ \\
\hline & Female & $2.33(2.15,2.52)$ & $2.16(1.99,2.34)$ & $2.28(2.10,2.48)$ & $2.18(2.00,2.37)$ & $2.34(2.15,2.53)$ \\
\hline \multicolumn{7}{|c|}{ All Respiratory Admissions } \\
\hline & & 1996 & 1997 & 1998 & 1999 & 2000 \\
\hline \multirow[t]{2}{*}{ Windsor } & Male & $2.19(2.05,2.35)$ & $1.98(1.85,2.13)$ & $1.96(1.83,2.10)$ & $2.05(1.92,2.20)$ & $1.63(1.50,1.76)$ \\
\hline & Female & $2.10(1.95,2.25)$ & $1.84(1.71,1.99)$ & $1.92(1.79,2.06)$ & $1.87(1.74,2.00)$ & 1.31 (1.2I, I.4I) \\
\hline \multirow[t]{2}{*}{ Sarnia } & Male & $2.83(2.54,3.14)$ & $2.29(2.03,2.57)$ & $2.15(1.91,2.42)$ & $2.19(1.95,2.47)$ & $1.94(1.70,2.19)$ \\
\hline & Female & $3.11(2.80,3.44)$ & $2.60(2.31,2.92)$ & $2.27(2.02,2.55)$ & $1.69(1.48,1.92)$ & $2.02(1.77,2.30)$ \\
\hline
\end{tabular}

* SAR $=$ observed admissions/expected admissions calculated from age-specific rates of London

Table 3: Missing data days and summary statistics of maximum daily pollutant levels in study period.

\begin{tabular}{|c|c|c|c|c|c|c|c|}
\hline \multicolumn{2}{|c|}{ Variable (unit) } & \multirow{2}{*}{$\begin{array}{l}\text { Mean } \\
3.35\end{array}$} & \multirow{2}{*}{$\begin{array}{c}\text { Standard Deviation } \\
2.96\end{array}$} & \multirow{2}{*}{$\begin{array}{c}\text { Minimum } / 24 \mathrm{hr} \\
0\end{array}$} & \multirow{2}{*}{$\begin{array}{c}\text { Maximum } / 24 \mathrm{hr} \\
28.63\end{array}$} & \multirow[t]{2}{*}{ AAQC $\dagger$} & \multirow{2}{*}{$\begin{array}{c}\text { Number of Missing Days } \\
12\end{array}$} \\
\hline $\mathrm{SO}_{2}(\mathrm{ppb})$ & London & & & & & & \\
\hline & Windsor & 7.36 & 5.06 & 0 & 37.50 & $100 / 24 \mathrm{hr}$ & 8 \\
\hline & Sarnia & 9.72 & 12.72 & 0 & 110.17 & & 4 \\
\hline \multirow[t]{3}{*}{$\mathrm{NO}_{2}(\mathrm{ppb})$} & London & 18.10 & 7.86 & 0 & 53 & & $54^{a}$ \\
\hline & Windsor & 23.50 & 7.59 & 6 & 50 & $100 / 24 \mathrm{hr}$ & 11 \\
\hline & Sarnia & 16.85 & 8.13 & 0 & 52 & & $100 c$ \\
\hline \multirow[t]{3}{*}{$\mathrm{O}_{3}(\mathrm{ppb})$} & London & 23.61 & 12.50 & 0 & 77 & & 7 \\
\hline & Windsor & 20.62 & 12.58 & 0 & 82 & $80 / \mathrm{hr}$ & 6 \\
\hline & Sarnia & 25.35 & 11.86 & 0 & 76 & & $54^{d}$ \\
\hline \multirow[t]{3}{*}{$\mathrm{CO}(\mathrm{ppm})$} & London & 0.16 & 0.30 & 0 & 3 & & 9 \\
\hline & Windsor & 0.60 & 0.44 & 0 & 3 & $3 / \mathrm{hr}$ & 5 \\
\hline & Sarnia & 0.27 & 0.29 & 0 & 1.4 & & $87^{b}$ \\
\hline
\end{tabular}

†Ambient Air Quality Criteria (Ontario Ministry of the Environment, 2000).

a Seven or more missing days in a row: $2000-$ Jan. 7-31; Feb. I-10

b Seven or more missing days in a row: $1998-$ Dec 2-31; $1999-$ Jan I-31

c Seven or more missing days in a row: 1997 - Oct. 8-16; 1998 - Sept. 24-30; Oct. 1-31; Nov. 1-10

d Seven or more missing days in a row: $2000-$ Nov. 8-16

e Seven or more missing days in a row: 1997 - Jan. 17-23

ical dose-response was specifically pronounced for respi- 
ratory hospital admissions.

The higher rates of morbidity in Sarnia point to the need for further investigation especially the role of pollution on hospital admissions in the city and surrounding communities. As indicated earlier, the geographic context of Sarnia which currently hosts $40 \%$ of Canada's chemical plants suggests that the city may be highly exposed, thus, facing severe pollution-related health problems.

Despite the fact that London and Windsor showed better results as compared to Sarnia, earlier studies that examined the association of ambient air pollution and hospital admissions in both cities reported some significant relationships between air pollution and cardiovascular and respiratory diseases. In London, Fung et al. reported that current day carbon monoxide and coefficient of haze produced significant percentage increase in daily cardiac admissions of $8.0 \%$ and $5.7 \%$ for people $<65$ years old respectively [20]. Fung et al. also assessed the association between daily ambient air quality and cardiovascular disease hospitalization in Windsor and reported, among other things, that short-term effects of $\mathrm{SO}_{2}$ are associated significantly with daily cardiac hospital admissions for people $\geq 65$ years of age [11]. The percentage increase in daily admission was $2.6 \%$ for current day sulphur dioxide, $4.0 \%$ for 2 -day mean level, and $5.6 \%$ for 3 -day mean. Similarly, Luginaah et al., also working in Windsor, reported significant associations between $\mathrm{NO}_{2}, \mathrm{SO}_{2}$, and $\mathrm{CO}$ and daily hospital admission of respiratory diseases [21]. In this analysis, both the case-crossover and timeseries analysis were performed. For females 0-14 years of age, there was one-day delayed effect of $\mathrm{NO}_{2}$ (relative risk $[R R]=1.19$, case-crossover method), current day $\mathrm{SO}_{2}(\mathrm{RR}$ $=1.11$, time-series), current day, one and two day delayed effects for CO by case-crossover $(\mathrm{RR}=1.15,1.19,1.22$, respectively). The findings from London and Windsor provided policy makers with current risks estimates of cardiovascular and respiratory hospitalizations as a result of poor ambient air quality in the two cities.

Substantial missing data values from the single existing continuous air quality monitoring station in Sarnia (Station ID: 14064) prevented our directly examining the association between air pollution and hospital admissions. For example, there were 100, 87, 54 and 25 missing days of seven or more days in a row for $\mathrm{NO}_{2}, \mathrm{CO}$, and $\mathrm{O}_{3}$, respectively, in the period under study. Hence, we cannot conclude that there is an unequivocal link between the higher rates of hospital admissions and air pollution in Sarnia. However, based on this and other studies in Windsor and London, we hypothesize that the increased admission rates in Sarnia are probably due to high levels of pollution which warrants government intervention.
In February of 2004, the Ontario Governments Environmental SWAT Team (now known as the Sector Compliance Branch) conducted an 11-month inspection sweep of Sarnia's industrial sector with the primary goal of ensuring that all facilities in that region were brought into compliance with environmental legislation (Ontario Ministry of the Environment, 2005). The decision to undertake a sweep of this magnitude came after a number of facilities in Sarnia's industrial sector had, during the previous year, allowed potentially harmful chemicals to spill into the St. Clair River; with two of those spills resulting in the temporary closures of water-intake facilities that supply drinking water to communities downstream (Ontario Ministry of the Environment, 2005). The objective of the deployment of the Environmental SWAT Team was to ensure that the operation of the petrochemical and related facilities was in compliance with all applicable provincial environmental legislative and regulatory requirements. The SWAT team inspected 35 petrochemical and related facilities located in Sarnia and in St. Clair Township. Thirty-four out of 35 facilities inspected during the sweep were found to be in non-compliance with one or more legislative and regulatory requirements. In total, more that 260 instances of non-compliance with environmental legislative and regulatory requirements were identified in the 35 facilities. The magnitude of the negligence found during the sweep further reinforces community concerns about the potential impact of the 'Chemical Valley'. (Ontario Ministry of the Environment, 2005). Hence, a critical look at the way ambient air quality and other pollutants are monitored in this area is warranted.

In a heavily polluted area, only consistent monitoring can lead to studies that would likely point to the right policy options among interested stakeholders. In fact, it is not surprising that at the local level, there seems to be a reluctance to acknowledge environmental exposure and public health issues $[9,23]$. Further epidemiological research is needed to verify our preliminary indications of harmful effects on people living in the 'Chemical Valley'. To shed more light on this missing link, a community health study is planned with self-reported health status and real time ambient air quality monitoring of several pollutants via a mobile unit.

By revealing the scale and significance of the problem through this regional comparison, we hope to stimulate the local community and industrial authorities into looking at how they can work together with the aim of implementing remedial measures. Government response to the environmental exposure issues and their associated health impacts in the border areas between Canada and the U.S.A. resulted in the unveiling of a joint strategy to improve the border air quality [22]. As part of this program, it may be useful to establish more long-term moni- 
toring stations in this region. Consistent monitoring will not only aid in the implementation of effective pollution control policies, but will also aid environmental risk management and communication with the public regarding both short and long term health effects.

\section{Conclusion}

Since hospital admissions rates were significantly higher in 'Chemical Valley' as compared to both London and Windsor, we hypothesize that these higher rates are pollution related. A critical look at the way ambient air quality and other pollutants are monitored in this area is warranted. Further epidemiological research is needed to verify our preliminary indications of harmful effects in people living in 'Chemical Valley'.

\section{Competing interests}

The author(s) declare that they have no competing interests.

\section{Authors' contributions}

KF and IL conceived the study and involved in the preparation of the manuscript. KG was involved in the interpretation of the results and preparation of the paper. All authors have read and approved the final manuscript.

\section{Acknowledgements}

This research was supported in part by a Discovery grant from the Natural Sciences and Engineering Research Council of Canada to K. Fung, a Social Science and Humanities Research Council grant and Canada Research Chair funding to I. Luginaah, and an Assumption chair in Canadian and American population health funding to KG. We also want to thank the Ontario Ministry of the Environment and the Canadian Institute for Health Information for providing us with the data.

\section{References}

I. Goldberg MS, Burnett R, Bailar JC III, Brook J, Bonvalot Y, Tamblyn R, Singh $R$, Valois MF: The association between daily mortality and short-term effects of ambient air particle pollution in Montreal, Quebec: I.Nonaccidental mortality. Environ Res 200I, A86: 12-25.

2. Goldberg MS, Burnett R, Bailar JC III, Brook J, Bonvalot Y, Tamblyn R, Singh $R$, Valois MF, Vincent $R$ : The association between daily mortality and short-term effects of ambient air particle pollution in Montreal, Quebec: 2. Cause-specific mortality. Environ Res 200I, A86:26-36.

3. Goldberg MS, Burnett R, Valois M, Flegel K, Bailar JC, Brook J, Vincent $\mathrm{R}$, Radon K: Associations between ambient air pollution and daily mortality among persons with congestive heart failure. Environmental Research 2003, 91:8-2011.

4. Lin M, Chen Y, Burnett RT, Villeneuve P, Krewski D: Effect of shortterm exposure to gaseous pollution on asthma hospitalization in children: a bi-directional case-crossover analysis. J Epidemiol Community Health 2002, 57:50-55.

5. Stern B, Jones L, Raizenne M, Burnett R, Meranger JC, Franklin CA: Respiratory Health Effects Associated with Ambient Sulfates and Ozone in Two Rural Canadian Communities. Environmental Research 1989, 49:20-39.

6. Burnett RT, Dales RE, Brook JR, Raizenne M, Krewski D: Association between ambient carbon monoxide levels and hospitalizations for congestive heart failure in the elderly in ten Canadian cities. Epidemiology 1997, 8: 162-167.

7. Burnett RT, Brook JR, Yung WT, Dales RE, Krewski D: Association between Ozone and Hospitalization for Respiratory Dis- eases in 16 Canadian Cities. Environmental Research 1997, 72:24-3I.

8. Burnett RT, Cakmak S, Brook JR: The effect of the urban ambient air pollution mix on daily mortality rates in I I Canadian cities. Canadian Journal of Public Health 1998, 89: 152-156.

9. Health Canada: Health Data and Statistics for the Population of the Region (1986-1992). Great Lakes Health Effects Program. A Technical Report for the Remedial Action Plan Community Public Works and Government Services, Ottawa; 1998.

10. Gilbertson M, Brophy J: Community Health Profile of Windsor, Ontario, Canada: Anatomy of a Great Lakes Area of Concern. Environmental Health Perspectives 200I, 109(6):827-843.

II. Fung KY, Luginaah I, Gorey KM, Webster G: Air pollution and daily admissions for cardiovascular diseases in Windsor, Ontario. Canadian J of Public Health 2005, 96:29-33.

12. Whelpdale DM: Large-scale atmospheric sulfur studies in Canada. Atmospheric Environment 1978, I 2:661.

13. Ontario Ministry of the Environment: Ontario Ministry of the Environment 2000. The Air Quality in Ontario [http:// www.ene.gov.on.ca/envision/air/AirQuality/2000report.htm]. Ontario Ministry of the Environment. Toronto, Canada January 20, 2007

14. PollutionWatch: Sarnia Area Facilities Rank High in Ontario's Top 10 List of Respiratory Polluters [http://www.pollutionwatch.org/pressroom/ releases/20050301.jsp]. List compiled by PollutionWatch released March I, 2005 January 20, 2007

15. Gilbertson M: Male cerebral palsy hospitalization as a potential indicator of neurological effects of methylmercury exposure in Great Lakes communities. Environmental Research 2004, 95(3):375-84.

16. Gilbertson M, Carpenter DO: An ecosystem approach to the health effects of mercury in the Great Lakes basin ecosystem. Environmental Research 2004, 95(3):240-6.

17. Mackenzie CA, Lockridge A, Keith M: Declining Sex Ratio in a First Nation Community. Environmental Health Perspectives 2005, I I 3(10): I 295-1298.

18. Luginaah IN, Fung K, Gorey K, Khan S: The Impact of 9/I I on the Association of Ambient Air Pollution With Daily Respiratory Admissions in Canada-US Border City, Windsor, Ontario. International Journal of Environmental Studies 2006, 63(4):50I-5I4.

19. Julious SA, Nicholl J, George S: Why do we continue to use standardized mortality ratios for small area comparisons? J of Public Health Medicine 200I, 23(1):40-46.

20. Fung K, Luginaah I, Gorey K, Webster G: Air Pollution and Daily Hospitalization for Respiratory and Cardiovascular Diseases in London, Ontario. International Journal of Environmental Studies 2005, 62(6):677-685.

21. Luginaah IN, Fung K, Gorey K, Webster G, Wills C: Association of ambient air pollution with respiratory hospitalization in a government designated "area of concern": the case of Windsor, Ontario. Environmental Health Perspectives 2005, I I 3:290-296.

22. Anderson D: Strengthening Our Cooperation for Cleaner Air: Canada-US Air Quality Cooperation. Speaking Notes for the Honourable David Anderson, Minister for the Environment, Canada. Border Air Quality Pilot Project Annoucement 2003.

23. Atari D, Luginaah I, Maticka-Tyndale E, Xu X, Fung K, Gorey K, Keith $M$, Reinhartz A: A Community Health Study in 'Chemical Valley', Sarnia, Ontario. In The 4th International Conference on Urban Health Toronto, Canada. October 26-28, 2005 